\title{
Further evidence for a bipolar risk gene on chromosome $12 q 24$ suggested by investigation of haplotype sharing and allelic association in patients from the Faroe Islands
}

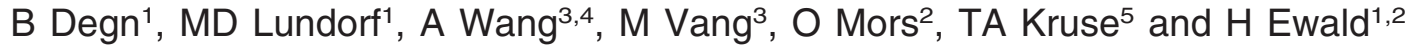 \\ ${ }^{1}$ Department of Biological Psychiatry; ${ }^{2}$ Department of Psychiatric Demography, Institute for Basic Psychiatric Research, \\ Psychiatric Hospital in Aarhus, DK-8240 Risskov, Denmark; ${ }^{3}$ Department of Psychiatry, National Hospital, Torshavn, Faroe \\ Islands; ${ }^{4}$ Copenhagen University Hospital, Denmark; ${ }^{5}$ Department of Clinical Biochemistry and Genetics, Odense \\ University Hospital, DK-5000 Odense, Denmark
}

\begin{abstract}
Keywords: manic depressive illness; genetic isolates; the Faroe Islands; bipolar affective disorders; chromosome 12; psychiatry; genetics
\end{abstract}

\begin{abstract}
A number of studies have strongly suggested a susceptibility locus for bipolar affective disorder on chromosome 12q24. The present study investigates for a shared chromosomal segment among distantly related patients with bipolar affective disorder from the Faroe Islands, using 17 microsatellite markers covering $24 \mathrm{cM}$ in the previously suggested region on chromosome 12q24. D12S342 showed possible allelic association to bipolar affective disorder ( $P$-value using CLUMP below 0.01). Increased sharing among cases of two-marker haplotypes were suggested at D12S1614-D12S342 $(P$ values using CLUMP below 0.01), and D12S2075D12S1675 ( $P$-values using CLUMP around 0.001). The region of most interest is around $6 \mathrm{cM}$ and bounded by markers D12S1614 and D12S1675 as suggested by the interesting two-marker haplotypes. This area contains the minimum interesting region between D12S342 and D12S1658 suggested by the previously reported haplotypes in the two Danish families with bipolar affective disorder. Molecular Psychiatry (2001) 6, 450-455.
\end{abstract}

Genetic factors are the most solid clues to the aetiology of bipolar affective disorder as evidenced by family and twin studies and two out of the five adoption studies. ${ }^{1,2}$ Specific genes and relevant DNA sequence variations involved in this disease have not yet been identified. Linkage studies have suggested a number of candidate chromosome regions, in particular chromosome $4 \mathrm{p} 16,{ }^{3}$ chromosome $4 \mathrm{q} 35,{ }^{4}$ chromosome $10 \mathrm{p},{ }^{5}$ chromosome $13 q 32,{ }^{6}$ chromosome $18 p,{ }^{7}$ and $18 q,{ }^{8,9}$ chromosome $21 \mathrm{q},{ }^{10}$ and the X-chromosome. ${ }^{11}$

We have earlier assigned a bipolar affective disorder susceptibility locus to 12 q24 by linkage analysis in two Danish families. ${ }^{12}$ Assuming a dominant mode of inheritance and only including patients with bipolar affective disorder as affected, the microsatellite marker D12S1639 gave a significant lod score of 3.37, empirical $P$-value of 0.00002 . This finding was further supported by non-parametric analyses using SimIBD, ${ }^{13-15}$ with $P$-values at D12S1639 of 0.00003 , when including patients with bipolar affective disorder and recurrent depression, and 0.005 when only including patients with bipolar affective disorder in the phenotype. This finding may support an earlier suggestive linkage finding with a lod score of 2.11 using Darier's disease as a phenotypic marker, which however is located more proximal on chromosome 12q23-24.1. ${ }^{16}$ Linkage results from independent studies on families from USA $^{6}$ as well as results from Canadian families ${ }^{17}$ and British families ${ }^{18}$ have further supported the existence of a susceptibility locus on chromosome 12q23-12q24.

Isolated populations have been useful for genetic mapping and final identification of genes for rare Mendelian disease ${ }^{19,20}$ and may also be more homogenous concerning genetic and non-genetic risk factors involved in complex diseases, thus facilitating the identification of risk factors. As the population of the Faroe Islands was founded by relatively few individuals and has been relatively isolated since its founding, it may be a well-suited population for genetic mapping of risk genes. Searching for shared chromosomal segments within a homogenous population has been a powerful approach for some rare Mendelian diseases ${ }^{21}$ and might be an advantage also in complex diseases. By selecting cases related around six to ten generations ago, a genome-wide scan searching for shared chromosomal segment may be performed on relatively few individuals using a few hundred DNA markers, ${ }^{21}$ as when using the lod score method on larger pedigrees. A few studies have found evidence of chromosome segment sharing for common complex diseases, including studies of bipolar affective disorder in the Costa Rican $^{9,22}$ and Faroese population. ${ }^{23}$

In order to confirm the presence of a susceptibility locus on chromosome 12q23-q24, to narrow the interval of interest and further aid the final identification of the susceptibility locus, we investigated 17 microsatellite markers spanning a region of $24 \mathrm{cM}$ (Table 1), in 14 patients with bipolar affective disorder (Figure 1) and 43 controls.

Results from analyses of single markers and twomarker haplotypes using CLUMP $^{24}$ are shown in Table 1. We considered $P$-values below 0.01 as interesting. Such $P$-values were found for marker D12S342, 
Table 1 Association analyses using CLUMP

\begin{tabular}{|c|c|c|c|c|c|}
\hline \multirow[t]{2}{*}{ Marker } & \multirow[t]{2}{*}{$c M$} & \multicolumn{2}{|c|}{ Single markers } & \multicolumn{2}{|c|}{$\begin{array}{l}\text { Two-marker } \\
\text { haplotypes* }\end{array}$} \\
\hline & & $T 1$ & $T 4$ & $T 1$ & $T 4$ \\
\hline D12S76 & 137 & 0.087 & 0.093 & & \\
\hline D12S1349 & 140 & 0.084 & 0.342 & 0.091 & 0.238 \\
\hline D12S1612 & 140 & 0.220 & 0.258 & 0.227 & 0.175 \\
\hline $\mathrm{D} 12 \mathrm{~S} 1614$ & 145 & 0.319 & 0.210 & 0.167 & 0.142 \\
\hline D12S342 & 145 & 0.007 & 0.007 & 0.007 & 0.003 \\
\hline D12S340 & 146 & 0.601 & 0.498 & 0.316 & 0.234 \\
\hline D12S1639 & 147 & 0.119 & 0.285 & 0.592 & 0.748 \\
\hline D12S324 & 147 & 1.000 & 1.000 & 0.430 & 0.546 \\
\hline D12S386 & 148 & 0.065 & 0.249 & 0.449 & 0.595 \\
\hline D12S1634 & 148 & 0.066 & 0.053 & 0.045 & 0.074 \\
\hline D12S307 & 148 & 0.187 & 0.202 & 0.084 & 0.061 \\
\hline D12S1658 & 148 & 0.474 & 0.393 & 0.211 & 0.221 \\
\hline GATA41E12 & 150 & 0.271 & 0.199 & 0.472 & 0.511 \\
\hline D12S2075 & 150 & 0.038 & 0.034 & 0.335 & 0.219 \\
\hline D12S1675 & 151 & 0.059 & 0.365 & 0.0007 & 0.001 \\
\hline D12S1659 & 156 & 0.373 & 0.472 & 0.138 & 0.186 \\
\hline D12S97 & 161 & 0.411 & 0.569 & 0.549 & 0.481 \\
\hline
\end{tabular}

The number of simulations performed was adjusted so the real chi-squared value was reached at least 20 times. Empirical $P$-values of the chi-squared T1 and T4 statistics are shown. The genetic map is from Marshfield (http://www. marshmed.org/genetics/).

* $P$-values for two-marker haplotypes reflect the marker in the respective row combined with the marker in the row above.

$P$-value 0.007 , and for two-marker haplotypes, D12S1614-D12S342, $P$-values of 0.003 and 0.007 , and D12S2075-D12S1675, $P$-value $\leq 0.001$.

As seen in Table 2 two different longer haplotypes, including most or all markers, were possibly present. Such a haplotype was probably present in cases A, H and $\mathrm{K}$ but only on one out of 86 control chromosomes, while cases $\mathrm{G}$ and $\mathrm{H}$, and zero out of 86 control chromosomes shared another haplotype. As seen in Table 2 a number of shorter haplotypes were also seen more than once. However, due to uncertain phases many of the longer haplotypes were potentially broken up and therefore we did not formally evaluate the significance of these haplotype frequencies statistically.

The present study yields further support for a risk allele for bipolar affective disorder in chromosome $12 q 24$.

The two different two-marker haplotypes were supported by empirical $P$-values derived by simulation using CLUMP ${ }^{24}$ and by a test assuming an approximate genealogical relationship between cases. In addition we applied Fisher's exact test on the most interesting of the specific haplotypes in these two segments.

The two-marker haplotype consisting of D12S1614D12S342 yielded $P$-values at or below 0.007 using CLUMP. The most interesting haplotype, the 1-7 haplotype, of D12S1614-D12S342 was present on five of the 28 case chromosomes and only three of the 84 control chromosomes, yielding a $P$-value of 0.0227 using Fisher's exact test (two-sided). If specifying that the cases were related six or seven generations ago, using the formulae of Houwen et $a l^{21}$ and assuming a size of the segment of $0.1 \mathrm{cM}$, the probability of sharing such a segment on 5 out of 28 chromosomes is less than 0.0003 (Table 3). It has to be remembered that cases on average were related around seven generations ago yielding a $P$-value below 0.00001 (Table 3). When using Fisher's exact test and the formulae derived from Houwen et $a l^{21}$ we have only evaluated the most frequent haplotype among cases. An advantage of CLUMP is that this program evaluated all the haplotypes, which are present in one test and may be significant also or only, if more than one haplotype is present more often among cases or if a protective allele is present more often among controls. As the frequency of the 1-7 haplotype of D12S1614-D12S342 in our control population is 0.036, this haplotype would occur by chance less than three out of 1000 times on five or more out of 28 chromosomes (Table 4) based on a simple binomial distribution. Tests with as well as

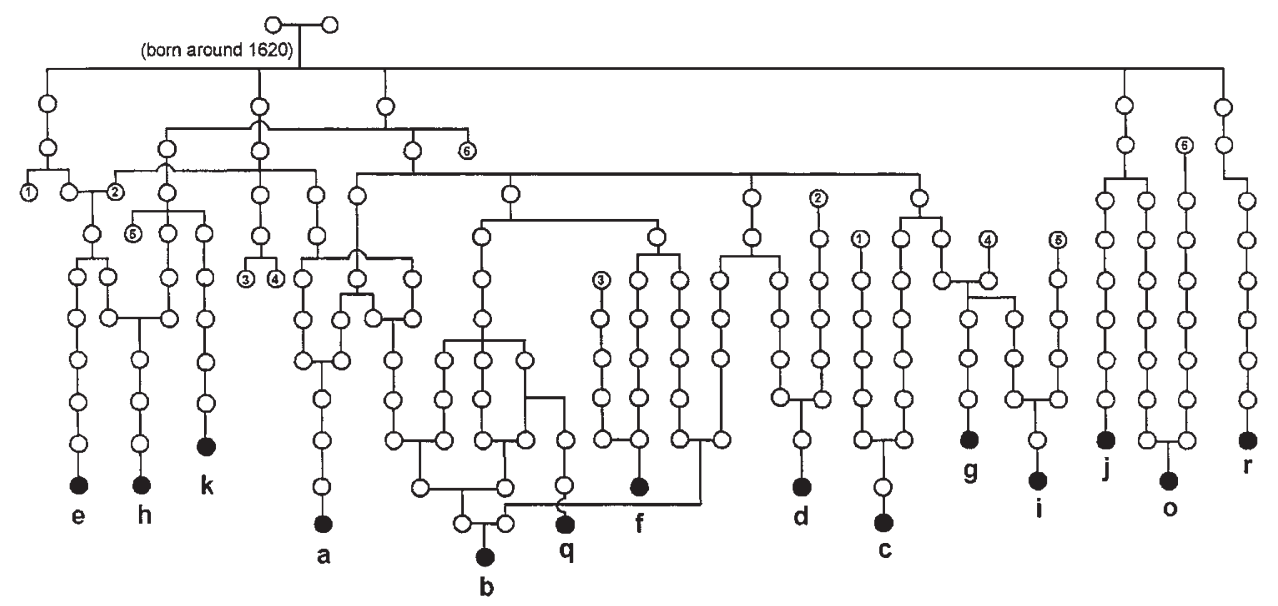

Figure 1 The 14 persons with bipolar affective disorder and their genealogical relationship. Identical numbers refer to identical persons. The sex of the individuals has been disguised. 
Table 2 Haplotypes of bipolar affective disorder patients using 17 microsatellite markers over the candidate region on chromosome 12q23-12q24. Paternally transmitted haplotype shown in bold.

\begin{tabular}{|c|c|c|c|c|c|c|c|c|c|c|c|c|c|c|c|c|c|c|c|c|c|c|c|c|c|c|c|c|c|}
\hline \multirow[b]{2}{*}{ D12S76 } & \multirow{2}{*}{$\begin{array}{c}c M \\
137\end{array}$} & \multicolumn{2}{|c|}{$A$} & \multicolumn{2}{|c|}{$B$} & \multicolumn{2}{|c|}{$C$} & \multicolumn{2}{|c|}{$D$} & \multicolumn{2}{|c|}{$E$} & \multicolumn{2}{|c|}{$F$} & \multicolumn{2}{|c|}{$G$} & \multicolumn{2}{|c|}{$H$} & \multicolumn{2}{|c|}{$I$} & \multicolumn{2}{|c|}{$J$} & \multicolumn{2}{|c|}{ K } & \multicolumn{2}{|c|}{$O$} & \multicolumn{2}{|c|}{$Q$} & \multicolumn{2}{|c|}{$R$} \\
\hline & & 4 & 4 & 5 & 4 & 4 & 5 & 8 & 1 & 1 & 1 & 1 & 1 & 1 & 1 & 5 & 1 & 3 & 5 & 6 & 3 & 4 & 2 & 3 & 2 & 1 & 5 & 5 & \\
\hline D12S1349 & 140 & o & 0 & 4 & 7 & 6 & 4 & $-6-$ & -10 & 9 & 6 & 4 & 6 & -6 & -7 & 5 & 6 & 12 & 10 & 7 & 7 & 5 & 6 & 2 & 4 & 6 & 4 & 10 & \\
\hline D12S1612 & 140 & 10 & 3 & 9 & 11 & 12 & 9 & $\mathbf{9}$ & 9 & $\mathbf{9}$ & 3 & 23 & 12 & 6 & 23 & 10 & 6 & 5 & 14 & 3 & 15 & 10 & 5 & 1 & 15 & 1 & 9 & 14 & \\
\hline D12S1614 & 145 & 1 & 2 & 1 & 6 & 2 & 2 & 2 & 2 & 1 & 1 & -1 & -6 & 1 & 1 & 1 & 1 & 4 & 3 & 5 & 6 & 1 & 3 & 1 & 3 & 2 & 1 & -3 & -1 \\
\hline D12S342 & 145 & 7 & 7 & 1 & 10 & 7 & 6 & 6 & 1 & 7 & 3 & 2 & 1 & 1 & 1 & 7 & 1 & 6 & 7 & $-1-$ & -10 & 7 & 9 & 1 & 7 & 6 & 1 & 7 & \\
\hline D12S340 & 146 & 2 & 2 & 2 & 2 & -2 & -3 & 3 & 2 & 5 & 2 & 1 & 2 & 2 & 2 & 2 & 2 & -2 & -3 & -3 & -2 & 2 & 2 & 2 & 3 & 3 & 2 & 3 & \\
\hline D12S1639 & 147 & 1 & 9 & 9 & 9 & $\mathbf{0}$ & 0 & 3 & 6 & 1 & 4 & 1 & 1 & 7 & 3 & 1 & 7 & 9 & 13 & 1 & 1 & 1 & 4 & 9 & 7 & 1 & 1 & 7 & \\
\hline D12S324 & 147 & 1 & 3 & 1 & 3 & 5 & 2 & -3 & -1 & 1 & 1 & 3 & 3 & 1 & 1 & 1 & 1 & -1 & -2 & 3 & 2 & 1 & 1 & 1 & 2 & 3 & 1 & 2 & \\
\hline D12S386 & 148 & 4 & 4 & 11 & 14 & 14 & 14 & 11 & 11 & 4 & 11 & 14 & 14 & 11 & 6 & -4 & $11-$ & $-11-$ & -14 & 14 & 14 & 4 & 13 & 16 & 11 & 14 & 11 & 11 & 11 \\
\hline D12S1634 & 148 & 4 & 2 & 3 & 3 & 1 & 4 & 2 & 2 & 2 & 2 & 3 & 3 & 2 & 2 & -4 & -2 & 2 & 2 & 4 & 2 & -4 & -2 & 2 & 2 & 3 & 2 & 2 & \\
\hline D12S307 & 148 & 4 & 4 & 2 & 2 & 2 & 7 & 2 & 2 & -4 & -2 & 2 & 2 & 2 & 2 & -4 & -2 & 2 & 2 & 4 & 2 & -4 & -2 & 2 & 2 & 2 & 2 & 2 & \\
\hline D12S1658 & 148 & 3 & 1 & 2 & 1 & 3 & 1 & -3 & -1 & 1 & 1 & 1 & 1 & 3 & 5 & 3 & 3 & -1 & -7 & 6 & 1 & 3 & 2 & 2 & 2 & 2 & 1 & 3 & \\
\hline GATA41E12 & 150 & 4 & 4 & 8 & 6 & 4 & 3 & 4 & 8 & 4 & 8 & 6 & 6 & 5 & 5 & 4 & 5 & 6 & 6 & 3 & 5 & 4 & 5 & 4 & 4 & 5 & 5 & 1 & \\
\hline D12S2075 & 150 & 5 & 5 & 5 & 4 & 5 & 8 & -5 & -6 & 5 & 7 & -5 & -6 & 5 & 6 & 5 & 5 & 3 & 6 & -2 & -5 & 5 & 4 & 5 & 5 & 4 & 6 & 6 & \\
\hline D12S1675 & 151 & 6 & 1 & 3 & 5 & 5 & 6 & -1 & -5 & -1 & -5 & 6 & 5 & 6 & 2 & 6 & 6 & 1 & 6 & 5 & 5 & -6 & -1 & 6 & 6 & 1 & 3 & 2 & \\
\hline D12S1659 & 156 & 2 & 2 & 5 & 1 & 1 & 2 & -2 & -7 & 2 & 1 & 2 & 5 & -2 & -6 & 2 & 2 & 2 & 5 & 1 & *2 & $\mathbf{0}$ & 0 & 5 & 3 & 3 & 1 & 1 & \\
\hline D12S97 & 161 & 1 & 3 & 1 & 7 & -3 & -1 & 1 & 1 & -1 & -8 & 1 & 1 & 1 & 1 & 7 & 1 & 1 & 1 & -1 & -6 & 1 & 4 & 1 & 1 & 4 & 4 & 1 & 1 \\
\hline
\end{tabular}

*We did not succeed in genotyping K for marker D12S1675, but K's father has the genotype 2-2 for this marker. The genetic map is from Marshfield (http://www.marshmed.org/genetics/). Uncertain phases are indicated by minus.

Table 3 The probability of a shared haplotype that does not contain a disease gene, of a certain size in cM is inherited from any out of the four founder chromosomes among 14 cases (28 chromosomes) related 6 or 7 generations (g) ago

\begin{tabular}{|c|c|c|c|c|c|}
\hline & $0.1 \mathrm{cM}$ & $1 \mathrm{cM}$ & $5 c M$ & $10 \mathrm{cM}$ & $24 c M$ \\
\hline \multicolumn{6}{|l|}{$g=6$} \\
\hline 2 out of 28 & 0.24278694 & 0.22257324 & 0.14771708 & 0.08393580 & 0.01267375 \\
\hline 3 out of 28 & 0.03319621 & 0.02880000 & 0.01487516 & 0.00609110 & 0.00033172 \\
\hline 4 out of 28 & 0.00327325 & 0.00268745 & 0.00108024 & 0.00031877 & 0.00000626 \\
\hline 5 out of 28 & 0.00024787 & 0.00019260 & 0.00006025 & 0.00001281 & 0.00000009 \\
\hline 6 out of 28 & 0.00001499 & 0.00001102 & 0.00000268 & 0.00000041 & 0.00000000 \\
\hline \multicolumn{6}{|l|}{$\mathrm{g}=7$} \\
\hline 2 out of 28 & 0.07432017 & 0.06629803 & 0.03903814 & 0.01915378 & 0.00192130 \\
\hline 3 out of 28 & 0.00503605 & 0.00421467 & 0.00185598 & 0.00062262 & 0.00001907 \\
\hline 4 out of 28 & 0.00024609 & 0.00019322 & 0.00006363 & 0.00001460 & 0.00000014 \\
\hline 5 out of 28 & 0.00000924 & 0.00000680 & 0.00000168 & 0.00000026 & 0.00000000 \\
\hline 6 out of 28 & 0.00000028 & 0.00000019 & 0.00000004 & 0.00000000 & 0.00000000 \\
\hline
\end{tabular}

without any assumptions concerning genealogy support the conclusion of increased sharing among patients.

The other interesting two-marker haplotype, D12S2075-D12S1675, yielded $P$-values at or below 0.001 using CLUMP. The 5-6 haplotype was present on six out of 24 case chromosomes but only on two out of 86 control chromosomes yielding a $P$-value of 0.0012 using Fisher's exact test (two-sided). Using the formulas of Houwen et $a l^{21}$ and assuming a size of the segment of $1 \mathrm{cM}$, the probability of sharing such a segment on six out of 28 chromosomes is 0.0000002 for cases related seven generations ago (Table 3). As the 56 haplotype of D12S2075-D12S1675 has a frequency of 0.025 in the control population, the probability of observing it by chance on six out of 28 chromosomes is below 0.00006 (Table 4). Once again evidence from tests with as well as tests without any assumptions concerning genealogy supports the conclusion of a significant increased sharing among patients.

Long haplotypes covering more or less the whole region, ie around $24 \mathrm{cM}$ long may be present, though with some uncertainty due to unknown phases (Table 2). The probability of finding a shared haplotype inherited identical by descent without a disease gene with a size about $24 \mathrm{cM}$ on two or three chromosomes out of 28 related chromosomes seven generations ago is less than 0.002 (Table 3). These longer haplotypes are reflected in several shorter haplotypes. The 1-7 haplotype of D12S1614-D12S342 and the 5-6 haplotype of D12S2075-D12S1675 are part of the probably longer haplotypes in $\mathrm{A}, \mathrm{H}$ and $\mathrm{K}$. Furthermore the 5-6 
Table 4 The probability of sharing a random marker allele or haplotype of a specific frequency $(q)$ by chance on $k$ out of $n$ chromosomes

\begin{tabular}{llll}
\hline$q$ & $k$ & $n$ & Probability \\
\hline 0.036 & 2 & 28 & 0.188842 \\
0.036 & 3 & 28 & 0.061119 \\
0.036 & 4 & 28 & 0.014265 \\
0.036 & 5 & 28 & 0.002557 \\
0.036 & 6 & 28 & 0.000366 \\
0.036 & 7 & 28 & 0.000043 \\
0.025 & 2 & 28 & 0.122318 \\
0.025 & 3 & 28 & 0.027182 \\
0.025 & 4 & 28 & 0.004356 \\
0.025 & 5 & 28 & 0.000536 \\
0.025 & 6 & 28 & 0.000053 \\
0.025 & 7 & 28 & 0.000004 \\
0.012 & 2 & 28 & 0.122318 \\
0.012 & 3 & 28 & 0.004186 \\
0.012 & 4 & 28 & 0.000318 \\
0.012 & 5 & 28 & 0.000019 \\
0.012 & 6 & 28 & 0.000001 \\
0.012 & 7 & 28 & 0.000000 \\
\hline
\end{tabular}

haplotype of D12S2075-D12S1675 is part of a different long haplotype seen in $\mathrm{G}$ and $\mathrm{H}$. The existence of several haplotypes might indicate the presence of allelic heterogeneity for bipolar affective disorder even in a genetically isolated population like the Faroese.

It is very difficult to assess statistical significance in genetic association studies and to make adjustments to statistical criteria as the amount and extent of linkage disequilibrium varies in different populations and genome regions. ${ }^{25}$ Though a number of tests have been performed we have not corrected the $P$-values for multiple testing, as the tests of different two-marker haplotypes are only partly independent. Only eight non-overlapping two-marker haplotypes can be made from the 17 markers and linkage disequilibrium among markers will further reduce the number of completely independent tests. As expected in an isolated population preliminary investigations of our control sample suggest that linkage disequilibrium is present among several of the adjacent as well as non-adjacent markers.

In conclusion the region of most interest is around $6 \mathrm{cM}$ and bounded by markers D12S1614 and D12S1675 as suggested by the interesting two-marker haplotypes and the different longer haplotypes. This area contains the minimum interesting region between D12S342 and D12S1658 suggested by haplotypes shared in the two Danish families with bipolar affective disorder. ${ }^{12}$ As suggested by simulations made by Te Meerman et $a l^{23,26}$ the probability that a segment of more than $5 \mathrm{cM}$ is shared identical by descent around a common disease gene on eg six chromosomes in patients related six generations ago is around 0.45 , ie it is not a rare event.

The present study is part of an ongoing genome-wide scan with more than 500 microsatellite markers. Preliminary results have suggested two other areas of

interest potentially containing risk alleles for bipolar affective disorder on chromosome 10q26 (unpublished) and $18 \mathrm{q} 23 .^{23}$

We will continue our search for allelic associations in other populations, in order to fine map the area of interest and hopefully identify a susceptibility locus for bipolar affective disorder.

We believe that the present study is encouraging as it yields independent statistical support for a susceptibility locus for bipolar affective disorder on chromosome 12q24. However, final proof of such a locus will have to await the finding of a functionally significant DNA sequence variation within the region.

\section{Methods}

Collection of cases and diagnostic criteria

The Faroese population has descended from a relatively small number of founders, especially from the western part of Norway and the British Isles, around $900 \mathrm{AD}$. The size of the population remained about 4000 until around $1800 \mathrm{AD}$ and has been reduced on a number of occasions due to diseases such as the plague, smallpox and periods of famine. In- and outmigration has been sparse. Today the population has increased to about 45000 .

We recruited 14 patients with bipolar affective disorder from the Department of Psychiatry, National Hospital in Torshavn, the capital of the Faroe Islands. Apart from the 14 included patients, three cases were not interviewed or included, as a genealogical relationship with the other cases could not be established or was unknown.

The included patients were interviewed by an experienced psychiatrist (AGW) using a brief version of the Present State Examination. ${ }^{27}$ Based on the hospital case notes and the interview, a clinical narrative was made for each patient. The final diagnosis was made as a consensus best-estimate by two experienced psychiatrists, Dr A Bertelsen and Dr O Mors, Risskov, Denmark, who independently reviewed the clinical narrative and if necessary other relevant material. Diagnosis was assigned on the basis of interviews and medical records according to ICD-10, Diagnostic Criteria for Research, and the fourth edition of the Diagnostic and Statistical Manual, Revised. ${ }^{28}$ Of the 14 included patients, all patients had bipolar affective disorder according to ICD-10 and bipolar disorder type I according to DSM-IV. As controls we recruited 43 parents and one offspring (trios) without known psychiatric diseases. The parents and offspring were collected from the same region of the Faroe Islands as the patients to enable a reliable estimation of marker allele and haplotype frequencies in the population.

\section{Genealogical assessment}

Cases related six to ten generations ago were sought in order to obtain a reasonable expected size of shared chromosomal segment around the putative disease gene(s). ${ }^{21,26}$ Using church and civic records of births, marriages and deaths, lineages were traced back as far 
454

as possible in order to determine if the patients were related and to determine the shortest possible genealogical distance between any pair of the patients' parents. Church records exist from either 1727 or 1750 depending on the sub-region, while incomplete church records and civic records exist from even earlier. At least one of each patient's parents could be connected in one or more ways to the other patients' parents. Figure 1 shows the patients and some of the ways of relating them. The father in generation I was born around 1620, the birth year of his wife is unknown. Some of the patients were even more closely related than shown in Figure 1.

The average number of generations relating two patients was 7.2, when pairs of patients were connected genealogically by the shortest possible distance through their parents. Only two pairs, E-G and B-Q were known to be related as closely as three generations ago. Cases B, E, F, G, H and J were each on average related to all other patients between 6 and 7 generations ago, A, C, D, I, K, O and Q similarly between 7 and 8 generations ago while $\mathrm{R}$ had an average of more than 9 .

\section{Genotyping}

Genomic DNA was prepared from venous blood using standard sucrose/triton-lysis protocol with sodium chloride/isopropanol precipitation. Polymerase chain reaction (PCR) amplification of microsatellites was performed using standard methods. The samples were automatically loaded and electrophoresed using the POP 4 protocol for ABI Prism 310 Genetic Analyser. GeneScan and Geno Typer programs were used to perform analysis of the allele sizes and allele scoring. Data management was performed by use of GenBase and GenoPedigree programmes (Applied Biosystems, Foster City, CA, USA). Two persons independently scored the genotypes according to CEPH family 1331 data. Markers were PCR amplified and genotyped a second time when showing non- Mendelian inheritance patterns within a family. The order of the microsatellites was based on information from public databases and on our own investigations including recombinants in ECPH families and DNA sequencing (unpublished results).

The haplotypes of the cases' (A, B, C, D, E, F, G, H, $\mathrm{I}, \mathrm{J}, \mathrm{K}$ and $\mathrm{O}$ ) chromosomes were assigned by tracing the parental origin of alleles. In order to reconstruct the haplotypes as completely as possible, both the parents and one child were genotyped. Due to the strict inclusion criteria based on severity of phenotype and geography, it was only possible to include two parents for four out of the 14 bipolar patients, while only one parent could be collected for eight patients. For the two remaining cases, $\mathrm{Q}$ and $\mathrm{R}$, haplotypes could be reconstructed by typing a child and the spouse of the patient. For the 43 control parents the haplotypes were reconstructed from one offspring. When haplotypes were reconstructed from one offspring it is possible that the reconstructed haplotype of interest has been partly broken by recombination events. However, as this will only happen with a reasonably low probability within any segment and as the probability that the crossing over will produce the specific haplotype of interest from two other haplotypes is probably even lower, this approach seems quite conservative.

\section{Statistical methods}

Allele frequencies and two-marker haplotype frequencies were compared between cases and controls using the CLUMP program. ${ }^{24}$ This program performs a Monte Carlo evaluation of significance levels for four chi-squared tables. It performs repeating simulations for all four chi-squared statistics, by generating tables having the same marginal totals as the one under consideration. Then the $P$-value is estimated by counting the proportion of times that a chi-squared value is as high or higher as the observed value associated with the chi-squared table under consideration. We focussed on the $\mathrm{T} 1$ and $\mathrm{T} 4$ statistical tests from CLUMP. The first chi-squared value (T1) is calculated from the observed chi-squared table, which contains counts obtained from the cases and controls. The fourth chi-squared value (T4) is the maximum chisquared value obtained from looking at all possible combinations of two-by-two tables made by clumping of the observed $n \times 2$ table.

In an isolated population the possibility of having inherited a chromosome segment, which does not contain a disease gene, from a common ancestor must be considered. The probability of detecting such a haplotype of a certain size, that does not contain a disease gene, among a number of cases related a known number of generations ago can be calculated from the formulae derived by Houwen et al. ${ }^{21}$ The probabilities of finding such a shared haplotype, $0.1 \mathrm{cM}, 1 \mathrm{cM}, 5 \mathrm{cM}$, $10 \mathrm{cM}$, or $24 \mathrm{cM}$ long, inherited identical by descent from a common ancestor couple six or seven generations ago, on more than three out of 28 chromosomes were between 0.00005 and 0.05 (Table 3). As such a specific segment may be inherited from each of the four ancestral chromosomes in the founding couple all probabilities are multiplied by four (Table 3).

Based on a binomial distribution the probabilities of observing a specific allele or shared haplotype on a number of chromosomes by chance, ie identical by state (IBS), are shown for selected allele or haplotype frequencies in Table 4.

\section{Acknowledgements}

The authors wish to thank senior psychiatrist Aksel Bertelsen, Psychiatric Hospital in Aarhus, for the thorough reading of all reports and medical records, and for performing the diagnostic evaluations according to ICD-10.

This work has been supported by: The Danish Medical Research Council; grant numbers 9601887 and 9902769. The Lundbeck Foundation; grants numbered 39/98 and 59/99. Psykiatrisk Forskningsfond. A grant from Einer Geert-Jorgensen foundation. A grant from Ingeborg and Leo Dannin. Ministry of Education, Cul- 
ture and Research, The Faroese Government; Research Fund of the Faroese Savings Bank, Torshavn, Faroe Islands; Danish Hospital Foundation for Medical Research, Region of Copenhagen, the Faroe Islands and Greenland. Grants from Simon Fougner Hartmann, EilifTrier-Hansen, and Dagmar Marshall foundations.

\section{References}

1 Bertelsen A, Harvald B, Hauge M. A Danish twin study of manicdepressive disorders. Br J Psychiatry 1977; 130: 330-351.

2 Tsuang M, Faraone S, Green A. Genetic epidemiology of mood disorders. In: Papolos DF, Lachman HM (eds). Genetic Studies in Affective Disorders. John Wiley and Sons: New York, 1994 pp 1-75.

3 Blackwood DH, He L, Morris SW, McLean A, Whitton C, Thomson $\mathrm{M}$ et al. A locus for bipolar affective disorder on chromosome $4 \mathrm{p}$. Nat Genet 1996; 12: 427-430.

4 Adams LJ, Mitchell PB, Fielder SL, Rosso A, Donald JA, Schofield PR. A susceptibility locus for bipolar affective disorder on chromosome 4q35. Am J Hum Genet 1998; 62: 1084-1091.

5 Foroud T, Castelluccio PF, Koller DL, Edenberg HJ, Miller M, Bowman E et al. Suggestive evidence of a locus on chromosome 10p using the NIMH genetics initiative bipolar affective disorder pedigrees. Am J Med Genet 2000; 96: 18-23.

6 Detera-Wadleigh SD, Badner JA, Berrettini WH, Yoshikawa T, Goldin LR, Turner $\mathrm{G}$ et al. A high-density genome scan detects evidence for a bipolar-disorder susceptibility locus on $13 \mathrm{q} 32$ and other potential loci on 1q32 and 18p11.2. Proc Natl Acad Sci USA 1999; 96: 5604-5609.

7 Berrettini WH, Ferraro TN, Goldin LR, Weeks DE, Detera-Wadleigh $\mathrm{S}$, Nurnberger JIJ et al. Chromosome 18 DNA markers and manicdepressive illness: evidence for a susceptibility gene. Proc Natl Acad Sci USA 1994; 91: 5918-5921.

8 Stine OC, Xu J, Koskela R, McMahon FJ, Gschwend M, Friddle C et al. Evidence for linkage of bipolar disorder to chromosome 18 with a parent-of-origin effect. Am J Hum Genet 1995; 57: 13841394

9 Freimer NB, Reus VI, Escamilla MA, McInnes LA, Spesny M, Leon $\mathrm{P}$ et al. Genetic mapping using haplotype, association and linkage methods suggests a locus for severe bipolar disorder (BPI) at 18q22-q23. Nat Genet 1996; 12: 436-441.

10 Straub RE, Lehner T, Luo Y, Loth JE, Shao W, Sharpe L et al. A possible vulnerability locus for bipolar affective disorder on chromosome 21q22.3. Nat Genet 1994; 8: 291-296.

11 Pekkarinen P, Terwilliger J, Bredbacka PE, Lonnqvist J, Peltonen L. Evidence of a predisposing locus to bipolar disorder on Xq24q27.1 in an extended Finnish pedigree. Genome Res 1995; 5: 105-115.

12 Ewald H, Degn B, Mors O, Kruse TA. Significant linkage between bipolar affective disorder and chromosome 12q24. Psychiatr Genet 1998; 8: 131-140.

13 Cottingham RWJ, Idury RM, Schaffer AA. Faster sequential genetic linkage computations. Am J Hum Genet 1993; 53: 252-263.
14 Ott J. Computer-simulation methods in human linkage analysis Proc Natl Acad Sci USA 1989; 86: 4175-4178.

15 Davis S, Schroeder M, Goldin LR, Weeks DE. Nonparametric simulation-based statistics for detecting linkage in general pedigrees. Am J Hum Genet 1996; 58: 867-880.

16 Craddock N, Owen M, Burge S, Kurian B, Thomas P, McGuffin P. Familial cosegregation of major affective disorder and Darier's disease (keratosis follicularis). Br J Psychiatry 1994; 164: 355-358.

17 Morissette J, Villeneuve A, Bordeleau L, Rochette D, Laberge C, Gagne B et al. Genome-wide search for linkage of bipolar affective disorders in a very large pedigree derived from a homogeneous population in Quebec points to a locus of major effect on chromosome 12q23-q24. Am J Med Genet 1999; 88: 567-587.

18 Detera-Wadleigh SD. Chromosomes 12 and 16 workshop. Am J Med Genet 1999; 88: 255-259.

19 de la Chapelle A, Wright FA. Linkage disequilibrium mapping in isolated populations: the example of Finland revisited. Proc Natl Acad Sci USA 1998; 95: 12416-12423.

20 Peltonen L. Positional cloning of disease genes: advantages of genetic isolates. Hum Hered 2000; 50: 66-75.

21 Houwen RH, Baharloo S, Blankenship K, Raeymaekers P, Juyn J, Sandkuijl L et al. Genome screening by searching for shared segments: mapping a gene for benign recurrent intrahepatic cholestasis. Nat Genet 1994; 8: 380-386.

22 Escamilla MA, Spesny M, Reus VI, Gallegos A, Meza L, Molina J et al. Use of linkage disequilibrium approaches to map genes for bipolar disorder in the Costa Rican population. Am J Med Genet 1996; 67: 244-253

23 Ewald H, Wang AG, Vang M, Mors O, Nyegaard M, Kruse TA. A halotype-based study of lithium responding patients with bipolar affective disorder on the Faroe Islands. Psychiatr Genet 1999; 9: 23-34.

24 Sham PC, Curtis D. Monte Carlo tests for associations between disease and alleles at highly polymorphic loci. Ann Hum Genet 1995; 59: $97-105$.

25 Schork NJ, Fallin D, Thiel B, Xiping X, Broeckel U, Jacob HJ, Cohen D. The future of genetic case-control studies. In: Rao DC, Province MA (eds). Genetic Dissection of Complex Traits. Academic Press: San Diego, 2001, pp 191-212.

26 te Meerman GJ, van der Meulen MA, Sandkuijl LA. Perspectives of identity by descent (IBD) mapping in founder populations. Clin Exp Allergy 1995; 25 (Suppl 2): 97-102.

27 Wing JK, Babor T, Brugha T, Burke J, Cooper JE, Giel R et al. SCAN. Schedules for Clinical Assessment in Neuropsychiatry. Arch Gen Psychiatry 1990; 47: 589-593.

28 American Psychiatric Association. Diagnostic and Statistical Manual of Mental Disorders, 4th edn. American Psychiatric Association: Washington, 1994.

Correspondence: H Ewald, Department of Psychiatric Demography, Institute for Basic Psychiatric Research, Psychiatric Hospital in Aarhus, Skovagervej 2, DK-8240 Risskov, Denmark. E-mail: he@psykiatri.aaa.dk

Received 3 November 2000; revised 16 January 2001; accepted 18 January 2001 